\title{
Methods for Detection of Asbestos-Cement Roofing Sheets**
}

\section{Introduction}

The issue of detection and utilisation of human-made materials present in the environment, which negatively affect human health, has become an important social problem in recent years. The example of such materials is a group of inorganic metamorphic fibrous minerals, commonly known as asbestos. Over the past a few dozen of years its pathogenic impact has been proven, which is related to the inhalation of airborne asbestos fibres, causing respiratory diseases.

Chemically, asbestos consists of hydrated silicates of various metals. Fibrous asbestos minerals can be divided into two basic groups: serpentinite group and amphibole group. Approximately $95 \%$ of the asbestos used in the industry is a chrysotile from the serpentinite group $\left(\mathrm{Mg}_{6}(\mathrm{OH})_{8}\left[\mathrm{Si}_{4} \mathrm{O}_{10}\right]\right)$, also known as white asbestos. Amphibole group, due to brittle and too thin fibres, has not been widely used. Characteristic properties of asbestos include the resistance to temperature changes and resistance to acids and caustic substances, non-flammability, durability in a wide $\mathrm{pH}$ range in cement matrix, low electrical conductivity [19].

Due to its characteristic properties, such as resistance to temperature changes as well as resistance to acids and caustic substances, asbestos has been widely used in construction. This material was used in building materials, such as: eternit (Fig. 1), i.e. corrugated asbestos-cement panels containing asbestos at the level of $10-13 \%$, flat pressed panels of similar asbestos content, KARO panels (Fig. 1), asbestos-cement high-pressure and sewer pipes, also used as ventilation ducts and internal combustion ducts (asbestos content of approximately 22\%), asbestos-cement fittings and large-size elements. Additionally, asbestos minerals are used in power engineering, transport and chemical industry.

* AGH University of Science and Technology, Faculty of Mining Surveying and Environmental Engineering, Krakow, Poland

** This study was made with financial support from grant no. 15.11.150.285, AGH University of Science and Technology 
a)

b)

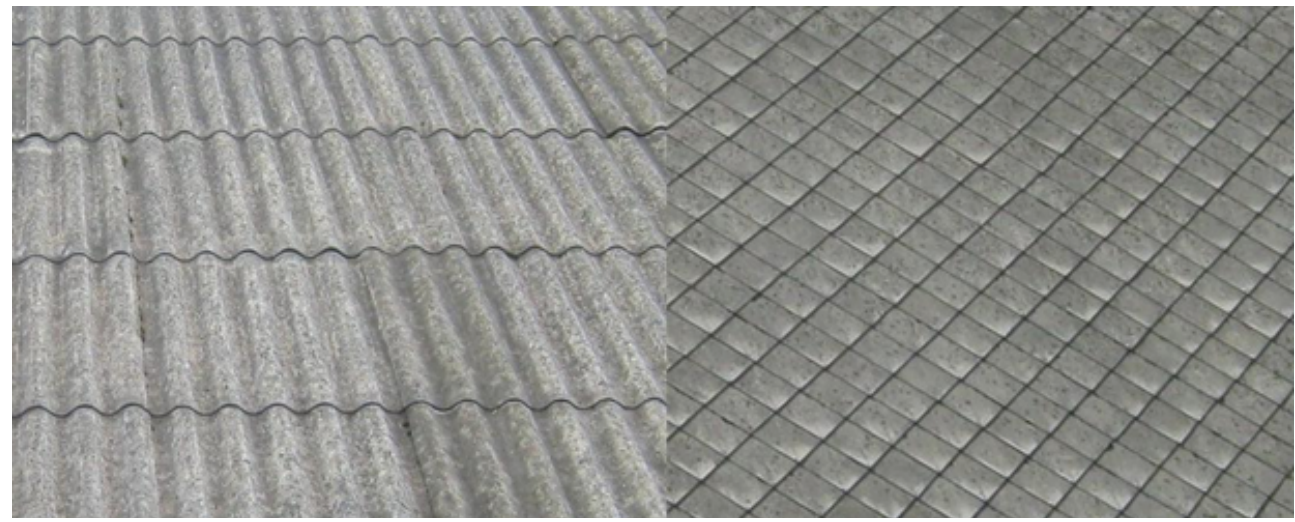

Fig. 1. Types of asbestos-cement roofing:

a) corrugated sheets - Eternit; b) KARO type of roof boards

It is estimated that currently in the Republic of Poland there are about 14.5 million tonnes of asbestos products, mainly eternit panels [13]. This is a huge problem due to very negative impact of asbestos products on human life. Pathogenic effect of asbestos results from inhalation of respirable airborne fibres. Respirable fibres are fibres with a length of more than $5 \mu \mathrm{m}$ and a maximum diameter of $3 \mu \mathrm{m}$ and the length-to-diameter ratio of over 3 to 1 . Due to their dimensions, the fibres penetrate deeply into the respiratory system. Natural mechanisms that clear the respiratory tract are not able to remove them, which may cause permanent damage to human body, for example: asbestosis, pleural thickening, neoplastic diseases such as lung cancer, mesothelioma of pleura and peritoneum (Fig. 2).

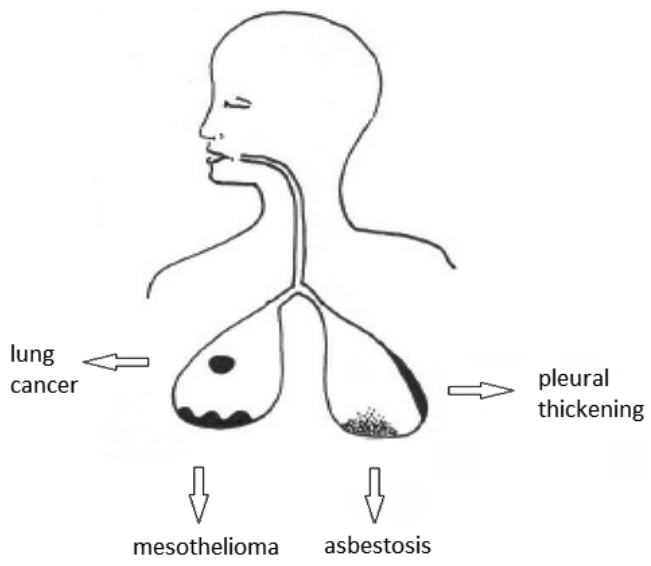

Fig. 2. Lung diseases caused by asbestos dust 
These diseases mentioned are characterized by a long latency period, manifesting after 10 to even 50 years after the exposure to asbestos [11]. Respirable asbestos fibres are undetectable by touch, and invisible to human eye, therefore the only warning for humans is to understand the existing risk and conscious adherence to the principles of safe handling of products and waste materials that contain asbestos. Additionally, it should be noted that there is no established threshold dose for asbestos dust air pollution, the passing of which to the body would constitute a threat to human health. Therefore, we should aim at the full elimination of asbestos dust from the environment, although its presence does not have to necessarily cause adverse health effects.

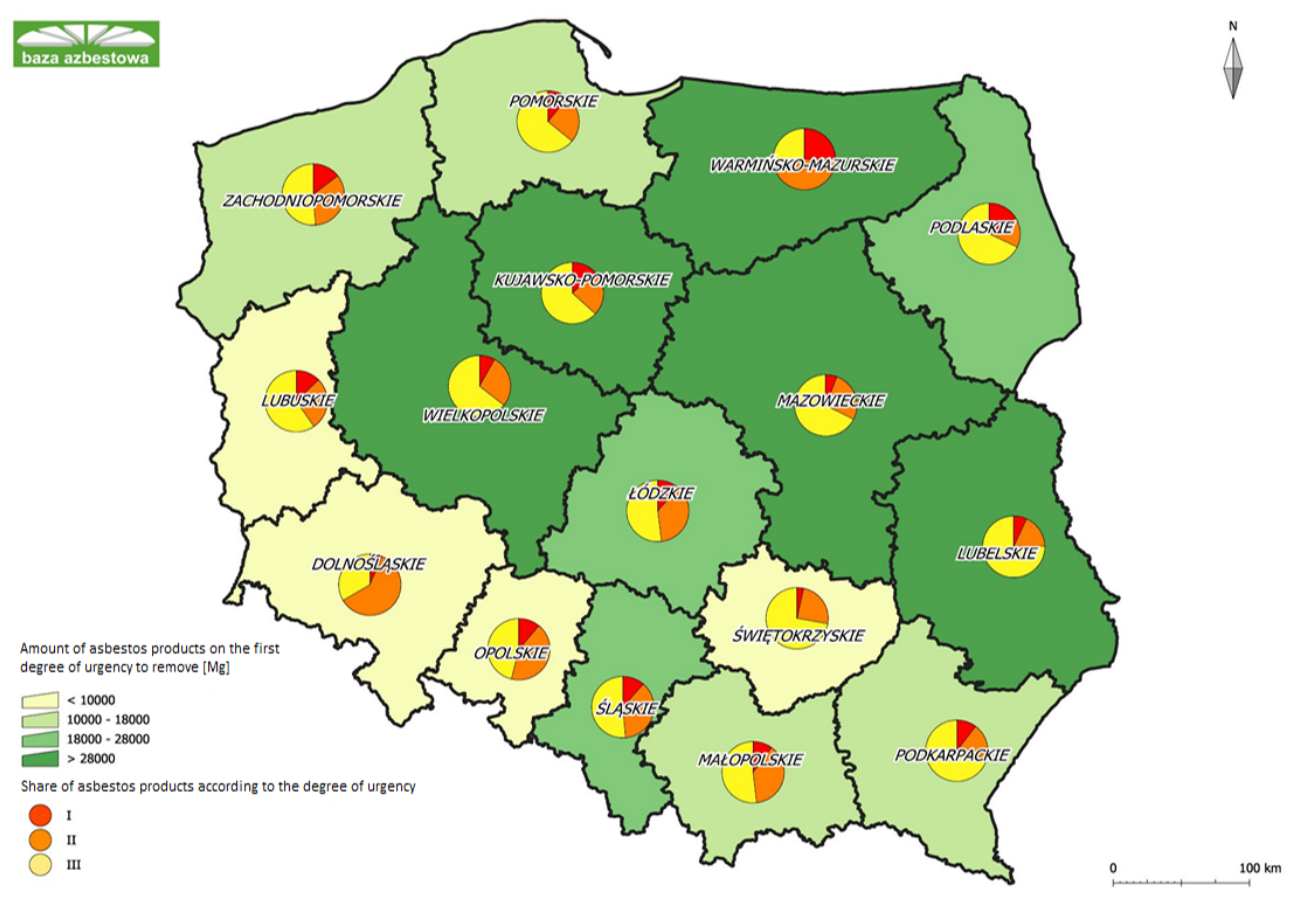

Fig. 3. Number of asbestos products taking account of the urgency of the removal in the various provinces in Poland

Source: http://www.bazaazbestowa.gov.pl/esip

In Poland, the first attempts to regulate the asbestos problem in legal terms were taken by means of the Act of 19 June 1997 on the prohibition of use of asbestos-containing products. With the Act, the ban was enacted on manufacturing, sale and use of asbestos products. Within the European Union the ban on the extraction of asbestos as well as on the production and processing of asbestos products was introduced by the Directive 2003/18/EC of 27 March 2003, which is a modified version of the earlier Directive 91/382/EEC of 25 June 1991. Ultimately, in accordance with 
the Directive 1999/77/EC of 1 January 2005, there is a total ban on the use of asbestos throughout the European Union. On 15 March 2010 the Council of Ministers passed a resolution to adopt the Programme for Asbestos Abatement in Poland for years 2009-2032.

The main objectives of the Programme mentioned are [13]:

- removal and neutralisation of asbestos-containing products,

- minimization of adverse health effects caused by the presence of asbestos in the country,

- elimination of harmful effects of asbestos on the environment.

The above objectives are to be implemented gradually until 2032, by which time the country should be completely free of asbestos. The Ministry of Economy is monitoring the progress of works carried out by means of asbestos database, which is a tool for collecting and processing information obtained from stock control of asbestos-containing products. One of the results presented is the analysis of the quantity of asbestos products, taking into account the urgency of their removal in different provinces (Fig. 3)

\section{Laboratory Analysis of Cement-Asbestos Samples}

Laboratory analysis was carried out by Bassani [1] on eternit samples in order to determine the relationship between mineralogical composition (using XRD method, SEM and FTIR analysis) and the radiation and absorption of electromagnetic spectrum (using spectrometers ASD and $\mu$ FTIR). Laboratory measurements were preceded by adequate preparation of samples collected, in accordance with health and safety requirements.

Qualitative analysis of the XRD patterns (X-ray diffraction) in all the samples showed the presence of calcite, gypsum, feldspars, serpentines, amphiboles, quartz, illite mica and other amorphous materials. During the activities carried out a problem was encountered in the evaluation of non-uniformly weathered samples. Additionally, it should be noted that the results obtained can be distorted due to the sensitivity of peak intensity of $X$-ray radiation on the directions and particle distribution in the sample $[2,10]$. An important conclusion from the works carried out is the fact that a multitude of asbestos fibres in the whole sample does not correlate with their large amounts on the surface. Figure 4 presents a comparison between absorption features detected by ASD measuring of asbestos-cement samples (VNIR and SWIR spectral ranges) and other minerals present in the samples: chrysotile, calcite, gypsum and quartz (the digital data derived from the USGS spectral library). The spectra analysis showed that the characteristic absorption feature of $2.327 \mu \mathrm{m}$ wavelength is detectable only in the asbestos material. Moreover, only the calcite spectrum indicates a similar absorption feature at approximate wavelength: $2.335 \mu \mathrm{m}$. 
For the other electromagnetic wavelengths some problems were encountered, such as too much noticeable effects of water vapor present in the atmosphere $(1.38 \mu \mathrm{m}$ wavelength), which eliminated the different ranges of the spectrum of its potential use in the research.

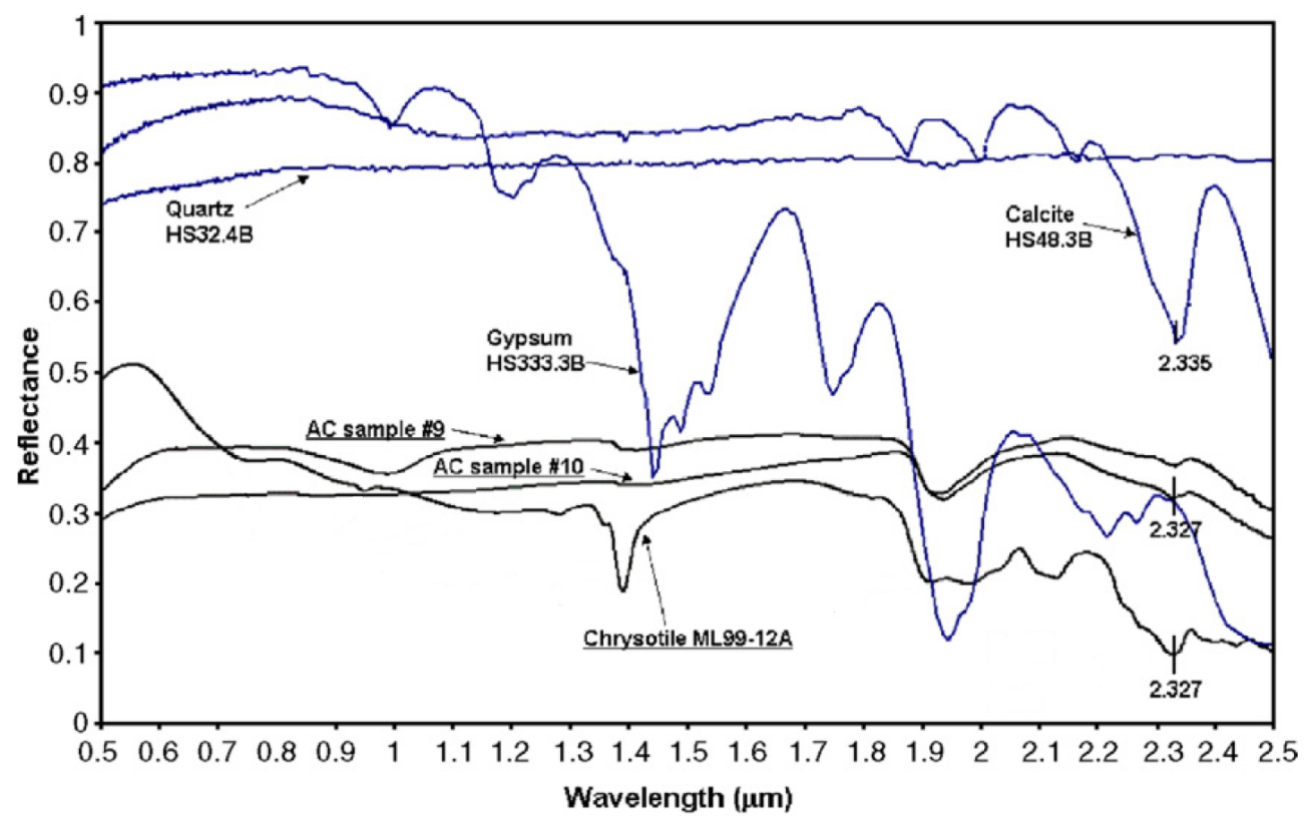

Fig. 4. A comparison between absorption features detected by ASD measuring of Asbestos-Cement samples no. 9 and no. 10 (VNIR and SWIR spectral ranges) and other minerals present in the samples: chrysotile, calcite, gypsum and quartz (the digital data derived from the USGS spectral library

Source: [1], modified

FT-IR analysis (using a Fourier transform spectrometer) indicated characteristic function of chrysotile fibres absorption between $9 \mu \mathrm{m}$ and $10.5 \mu \mathrm{m}$. Figure 5 presents the reflectance in the TIR spectral region for a sample containing on its surface the largest number of asbestos fibers - sample AC no. 16 (radiation measurements made by a $\mu$ FTIR spectrometer), and minerals such as chrysotile [14], calcite, gypsum and quartz [15]. The characteristic asbestos and chrysotile absorption feature is focused on $9.44 \mu \mathrm{m}$ wavelength. A controversial mineral, which distorts the results obtained, is quartz, due to similar absorption function at this wavelength.

The results of the analyses carried out show the possibility of using remote sensing to identify asbestos-cement roofing sheets, with the use of two spectral ranges: SWIR with $2.32 \mu \mathrm{m}$ wavelength and TIR with $9.44 \mu \mathrm{m}$ wavelength. 


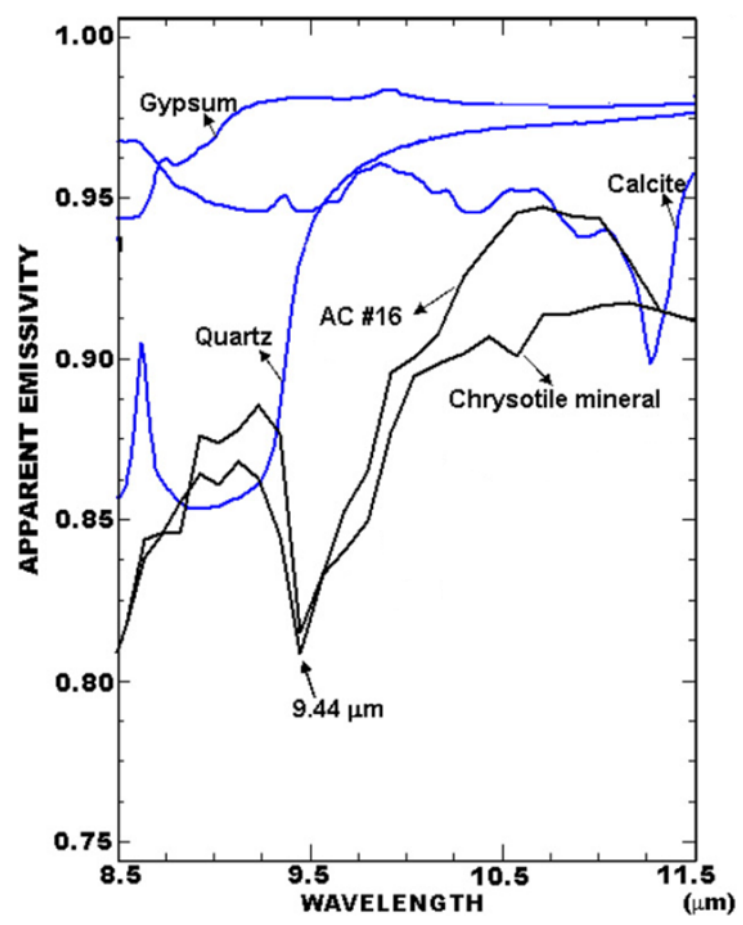

Fig. 5. A comparison absorption features detected in the TIR spectral region for Asbestos-Cement sample no.16 (radiation measurements made by $\mu$ FTIR spectrometer) and minerals such as chrysotile [14], calcite, gypsum and quartz [15]

Source: [1], modified

\section{Identification Using Hyperspectral Data}

Hyperspectral remote sensing technique provides scene images in a very large number of spectral channels with narrow ranges of wavelengths. In view of the fact that the hyperspectral imaging in most cases is conducted from the air, apart from high spectral resolution the data also has a high spatial resolution of a few meters. According to Small [16] and Welch [20], the size of ground pixel used for urban areas should not exceed $5 \mathrm{~m}$. In such case, the values recorded for individual pixels are not mixels of a very complex spectral response.

The studies presented, carried out by $[1,9,5]$ referred to the area of Italy. The analysed images were obtained by means of MIVIS (Multispectral Infrared and Visible Imaging Spectrometer) air hyperspectral scanner, which is owned by CNR (National Research Council of Italy). MIVIS is a modular device which records radiation reflected from the Earth's surface in the visible range (20 channels), in the near infrared range ( 8 channels), in the mid-infrared range (64 channels) and in the thermal infrared range (10 channels) with a spatial pixel resolution smaller than 5 meters (Tab. 1). 
Table 1. MIVIS sensor characteristics

\begin{tabular}{|c|c|c|c||}
\hline Spectrometer & Spectral coverage & Channels & Bands ranging $[\mu \mathrm{m}]$ \\
\hline \hline I & visible & 20 & $0.43-0.83$ \\
\hline II & near infrared & 8 & $1.15-1.55$ \\
\hline III & shortwave infrared & 64 & $2.0-2.5$ \\
\hline IV & thermal infrared & 10 & $8.2-12.7$ \\
\hline
\end{tabular}

Source: [5]

One of the first stages of works that enable to use hyperspectral data is to determine spectral characteristics of the individual materials. For this purpose, in accordance with Bassani [1] the field spectral analyses were carried out and a distinction was made between the spectrum of asbestos-cement roofing sheets and the surrounding background, and other types of materials. Additionally, a spectral profile library was created for the typical building materials, useful for calibration and validation of the remote sensing data. During field measurements, the spectrum was recorded using an analytical spectral device with full spectrum range (Analytical Spectral Devices (ASD) Full-Range (FR) spectrometer) and a radiometer (Design and Prototypes micro-Fourier transform infrared radiometer ( $\mu$ FTIR), Model 102). The resulting characteristic reflection and radiation spectra represented 29 unique surfaces ( 7 different roofing materials, 15 asbestos-cement samples with different degrees of degradation, 7 surfaces representing the background - soil and vegetation). Using ENVI 4.1 software the spectrum obtained was compared with the data obtained with MIVIS (Fig. 6).

a)

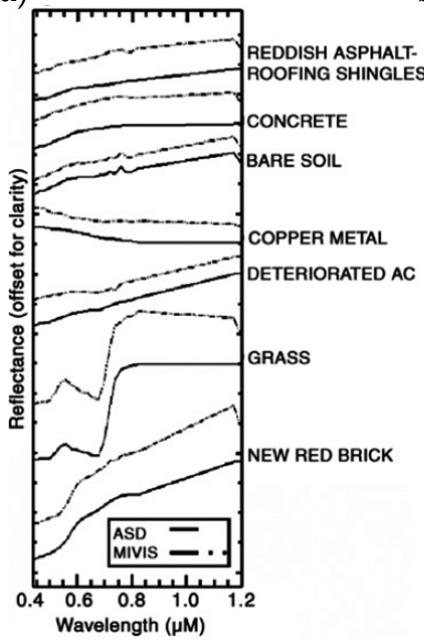

b)

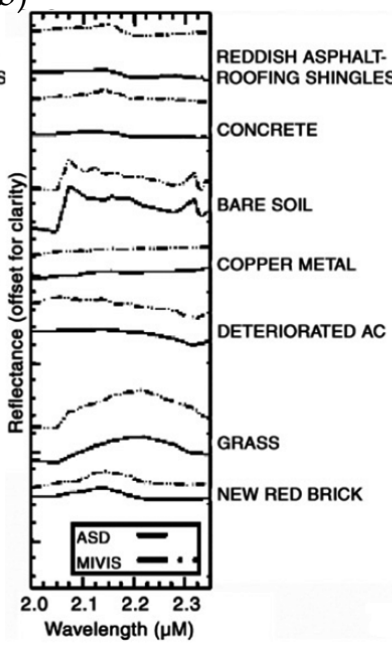

c)

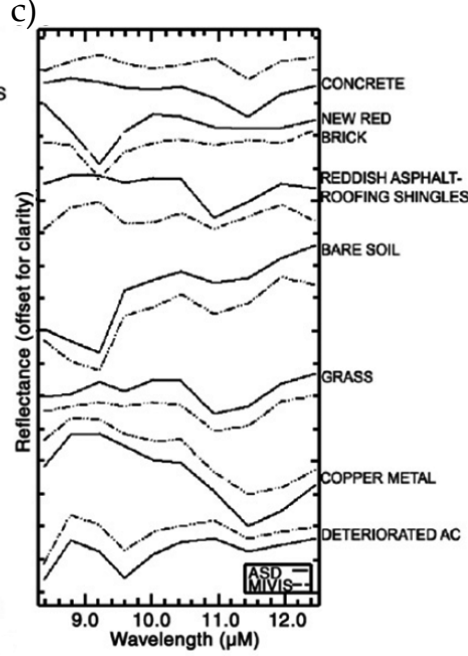

Fig. 6. Comparison of (a) VNIR, (b) SWIR and (c) TIR field mean spectra of typical roof materials, soil and vegetation. Spectra are offset vertically for clarity. Reflectance and emissivity field spectra were convolved to the 2003 MIVIS instrument sampling interval and bandpass (dash-dots outlined) 
The next step of the described studies was determining location of asbestos roofing sheets in different images and checking accuracy of the maps obtained. Marino [9] proposed two independent methodological approaches, such as the traditional image classification and the classification using the so-called spectral libraries.

Traditional image classification is based on a priori knowledge on different types of land surface use. The ability to distinguish between various roofing sheets can be achieved through field works, analysis of aerial photographs and other independent sources of information. Areas of training, called "sample set", are small areas assigned to a certain class as its representative. For the presented analyses the following classes were distinguished: asbestos-cement roofing sheets at different levels of weathering, aluminium, asphalt, pure concrete. The division of asbestos cement for two classes (low weathered asbestos concrete and high weathered asbestos concrete) (Tab. 2) was motivated by the variation of spectral response for each of them [9]. This distribution is also important because of the urgency of removal and disposal of this material. In the first place the appropriate action on the high weathered asbestos elements should be taken, because under the influence of external factors they release volatile asbestos fibers dangerous to the human health.

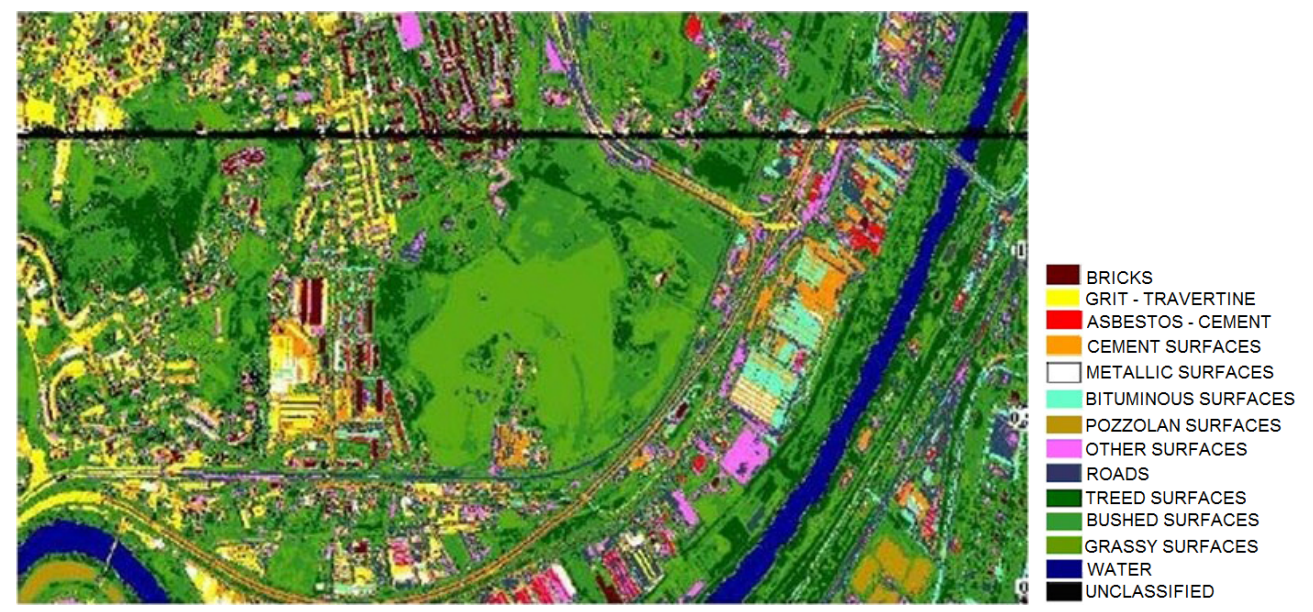

Fig. 7. Classification of materials by the SAM method. Thirteen classes of different materials were highlighted, among which the vegetation and the River Tiber, which represent different spectral typologies present in the view (the lack of a scanning line in the view is due to a recording error)

Source: [5]

The classification process was carried out using SAM algorithm (Spectral Angle Mapper) (Fig. 7). This algorithm treats spectral profile as vectors in space of a dimension equal to the number of individual bandwidths and determines similarities between two spectra by calculating the $n$-dimensional angle ( $n$ - number of image 
channels) between them [18]. SAM algorithm needs reference input spectra determined on the basis of practice areas. Then it calculates the angular distances between the spectrum of each pixel in the image and the reference spectrum. The principle of assigning pixels to each category consists in selecting class to which the spectral angle is the smallest.

The accuracy of classification obtained was tested using the method of error matrix. The results obtained are shown in Table 2, using the test data from the ground-based measurements. Overall accuracy of the classification performed is greater than $85 \%$. The largest discrepancies relate to incorrect classification of asphalt surfaces. Ultimately, however, the results presented confirm the possibility to make effective use of this method to identify asbestos-containing materials.

Table 2. Confusion matrix for the Image Based Classification

\begin{tabular}{|c|c|c|c|c|c|c|c|}
\hline & \multicolumn{6}{|c|}{ Ground truth } \\
\hline & & $\begin{array}{l}\text { low weathered } \\
\text { asbestos concrete }\end{array}$ & $\begin{array}{l}\text { high weathered } \\
\text { asbestos concrete }\end{array}$ & $\begin{array}{c}\text { alumi- } \\
\text { num }\end{array}$ & asphalt & $\begin{array}{c}\text { plain } \\
\text { concrete }\end{array}$ & total \\
\hline & unclassified & 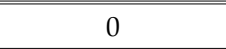 & 28 & 1 & 3 & 30 & 62 \\
\hline \multirow{6}{*}{ 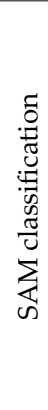 } & $\begin{array}{l}\text { low weathered } \\
\text { asbestos } \\
\text { concrete }\end{array}$ & 168 & 112 & 0 & 12 & 0 & 292 \\
\hline & $\begin{array}{l}\text { high weathered } \\
\text { asbestos } \\
\text { concrete }\end{array}$ & 21 & 798 & 0 & 1 & 0 & 820 \\
\hline & aluminum & 7 & 0 & 91 & 0 & 8 & 106 \\
\hline & asphalt & 3 & 3 & 0 & 202 & 0 & 208 \\
\hline & plain concrete & 1 & 1 & 0 & 15 & 148 & 165 \\
\hline & total & 200 & 942 & 92 & 233 & 186 & 1653 \\
\hline
\end{tabular}

Source: [9]

Another described classification, which is based on spectral libraries, is a supervised method of creating maps using registered reflections of electromagnetic radiation. This approach does not require prior field orientation and defining practice areas. The individual spectra are obtained from laboratory analyses or spectral measurements in situ. The final step is the direct comparison of the obtained sets of data with the values of spectral responses, in order to identify specific materials in the analysed image.

In case of direct comparison of individual results, the impact of atmosphere on hyperspectral data should be minimalized in the first instance. The study carried out by Marino [9] considers the use of ATmosphere Removal Program (ATREM). This program was originally designed to improve the data from AVIRIS (Airborne Visible / Infrared Imaging Spectrometer - Airline spectral imaging in the visible / infrared), but can also be adapted to other hyperspectral sensors [6]. 
The next step performed by Marino [9] was the transformation of Maximum Noise Fraction (MNF), which corrects the MIVIS data to the proper dimension of hyperspectral data, removes noise and reduces calculating requirements of the equipment used in further processing. The use of MNF transformation results in creating a new hyperspectral image, the channels of which are sorted according to the image quality [7]. For further studies, described by Marino [9], the first twelve components of MNF were selected, which contained most information from the original images. The resulting MNF image was analysed using the Mixture Tuned Matched Filtering (MTMF) mapping method. The use of this filter ensures quick tool to detect specific dependencies based on spectral libraries, or "clean" spectral images (images which do not contain information created as an environment reaction, e.g. impact of the atmosphere). This approach increases the importance of "clean" spectral images and at the same time suppresses the influence of the unknown background [8]. What is more, the result of the algorithm performed is the image of "infeasibility". This image is used to assign "false alarms" to the pixels of high infeasibility. A pixel which is correctly classified has a high score of matching and a low value of infeasibility [3]. Completed image processing helped to identify the set of pixels with very similar spectral profiles to the spectra of asbestos-cement material. Finally, the set of those pixels was used as training pixels in SAM classification.

Accuracy of the classification carried out according to the above scheme was evaluated through selecting 5000 control points randomly distributed on the resulting image. Comparison of the classified image with the field control established accuracy at the level higher than $90 \%$. The authors again indicated the problem of distinguishing the asbestos cement from bituminous materials, due to similar spectral profiles of both materials.

Based on the experiences of other research teams it can be noted that there is a possibility to use spectral features for detection of asbestos-cement roofs on a high level of $90 \%$. The identification can be carried out using specific, very narrow spectral ranges or using a wider range of spectrum recorded as hyperspectral images.

\section{Identification on Satellite Data}

The next step in order to identify the asbestos-cement roofs should be an attempt to transfer international experiences to the area of Polish science. As it turns out, it is not easy, due to limited access to appropriate hyperspectral imaging. However, on account of the legal regulations, mentioned at the beginning, which Poland committed to obey, the problem of identification and utilisation of asbestos-cement roofing sheets requires rapid response. Therefore, the idea of starting analyses based on satellite data has been created. In such case, the satellite images should be acquired which meet a few conditions, e. g. the ground pixel of the image cannot exceed $5 \mathrm{~m}[16,20]$. 
The research using satellite data to the land cover classification was presented by Pinho [12]. Quickbird scene was used in this work: a panchromatic image with $0.60 \mathrm{~m}$ spatial resolution and a multispectral image with $2.4 \mathrm{~m}$ spatial resolution. In the study twelve classes of land cover was obtained, for which the kappa coefficient was close to 0.5 value. Among the separated land cover types, two classes involved asbestos: dark concrete/asbestos roof and medium tone concrete/asbestos roof. It seems that on the basis of the results shown in this work, it is not possible to separate the asbestos roofing sheets with this type of imaging due to their visual similarity to large cement surfaces. Considering the previously acquired knowledge, in case of multispectral satellites, recording of individual channels should refer to a very narrow wavelength range of $2.32 \mu \mathrm{m}$ or $9.44 \mu \mathrm{m}$. Another convenient solution would be the availability of hyperspectral images from the satellite level, but of the appropriately small pixel. Taking these limitations into account, the available multispectral commercial satellites QuickBird, GeoEye-1, WorldView-2 can be taken into consideration. QuickBird satellite has a properly small ground pixel $(2.4 \mathrm{~m})$, while the recorded spectral ranges do not contain the appropriate length of the electromagnetic wave. An analogical problem refers to the satellite GeoEye-1, which has a pixel size of $1.65 \mathrm{~m}$. The last satellite, WorldView-2, also provides data with the ground pixel of $1.65 \mathrm{~m}$, while the appropriate wavelength is recorded in a range that is too wide, as near-IR2: $860-1040 \mathrm{~nm}$, which makes it impossible to use it for identification. Other available satellite missions, which fulfil the requirement of pixel size, also do not have one of these two mentioned spectral ranges. What is more, there were no available satellite images of missions listed above, and based on the knowledge acquired it would be pointless to purchase them. Therefore, no attempts to carry out analysis from the satellite level were carried out.

\section{Identification on Orthophotomap}

After reviewing the possibility of using satellite images and ascertaining that such analyses would not produce desired effect, it was decided to use the imaging from the air level. The usefulness of a digital aerial imagery for supporting inventory works associated with the detection of asbestos was studied in the Mineral and Energy Economy Research Institute of the Polish Academy of Sciences [4, 17]. The performed work, which was done in Ogrodzieniec, confirm the usefulness of the aerial imagery to the initial location of asbestos contaminated areas. Therefore, undertaken own research based on orthophotomaps which additionally advantage is significant coverage in the country (Fig. 8). In case of creating a consistent and efficient system for the identification of asbestos-cement roofing sheets with use of these maps, there would be a possibility of using this system on a large scale. 


\section{Legend: \\ PIXEL

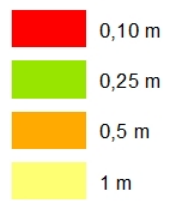

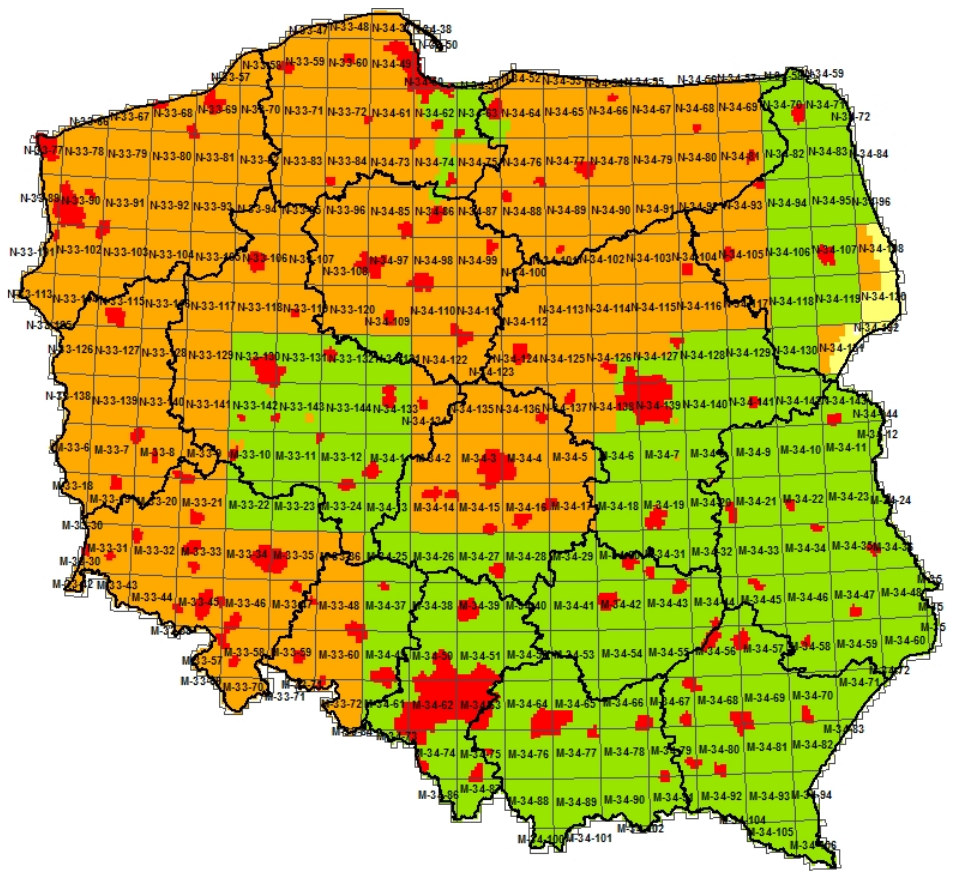

Fig. 8. Pixel size on available orthophotomaps in PZGIK (December 2013)

Source: http://www.codgik.gov.pl

The aim of preliminarily conducted studies was the attempt to find a method that would allow to perform the classification of spectral and textural character, similar to the interpretation performed by human visual system. The analyses began with photo interpretation with concurrent screen digitalization on orthophotomaps of different ground pixels for part of the Małopolska province. First studies were conducted on orthophotomaps of $5 \mathrm{~cm}$ ground pixel, which allowed the operator to gain ability to recognize different roofing materials with high efficiency. The target result of the works carried out was to determine the possibilities of automating the process of asbestos-cement roofing identification. It turned out, unfortunately, that there is no basis for the development of such system. The problem encountered resulted from the fact that some materials had similar colour to asbestos products, e.g. cement slates (Fig. 9).

With the use of additional image properties, such as structural and textural features, there are reasons to make an attempt to build the target system. In such case, what should be considered is the availability of high resolution images, which is not common (Fig. 8), and because of that the effort made in order to achieve satisfactory results might not be proportionate to the effects. Then, analogical actions were performed on orthophotomaps of $25 \mathrm{~cm}$ ground pixel, the current range of which covers half of the country (Fig. 8). In this case, the identification of asbestos-cement 
roofs was not so obvious and the process of photo interpretation has not brought the expected results. The human eye was able to identify the roofs, which may contain asbestos, but the effectiveness of the works carried out was not satisfactory (Fig. 10). Another aspect that adversely affected the analyses undertaken was a different degree of sunlight intensity at different orthophotomaps and diverse incidence angle of light rays on different roof surfaces (Figs 9,10). This resulted in the inability to systematize information recorded for asbestos-cement roofing sheets.

a)

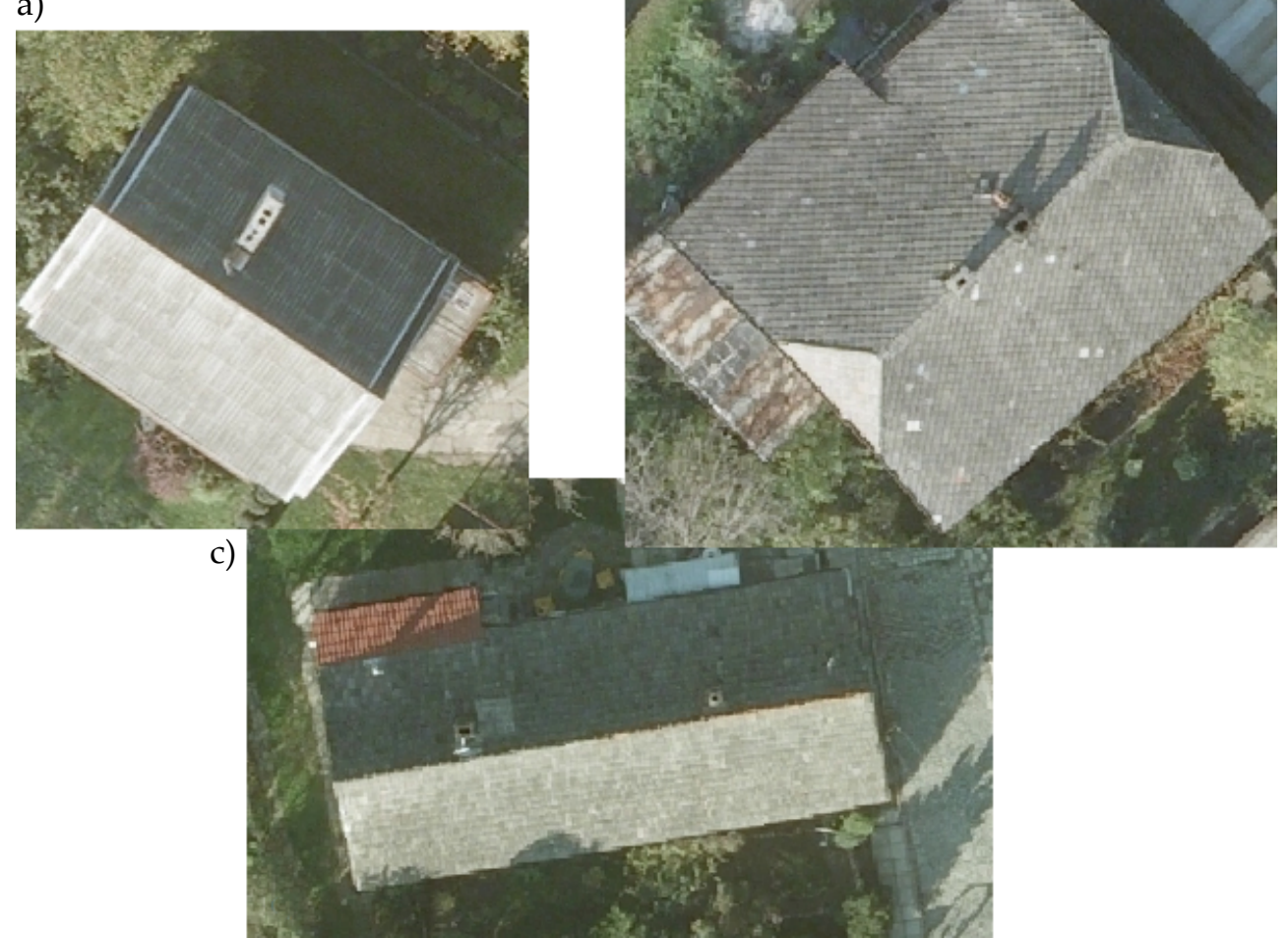

Fig. 9. Examples of roof coverings on orthophotomaps with $5 \mathrm{~cm}$ pixel size, the display scale 1:250:

a) Eternit; b) KARO board; c) concrete roof tiles

During the works carried out, on both orthophotomaps about 200 roofs, situated along the main roads of the province, were vectorised. Verification of actions performed was carried out based on Google Street View application (Fig. 11). This service can also be used for visual detection of asbestos elevation of buildings, which amount is still significant in Poland. However, the limitations of this application should be taken into consideration, such as the availability of made journeys or an override of the facades by the bushes, trees and high fences. 


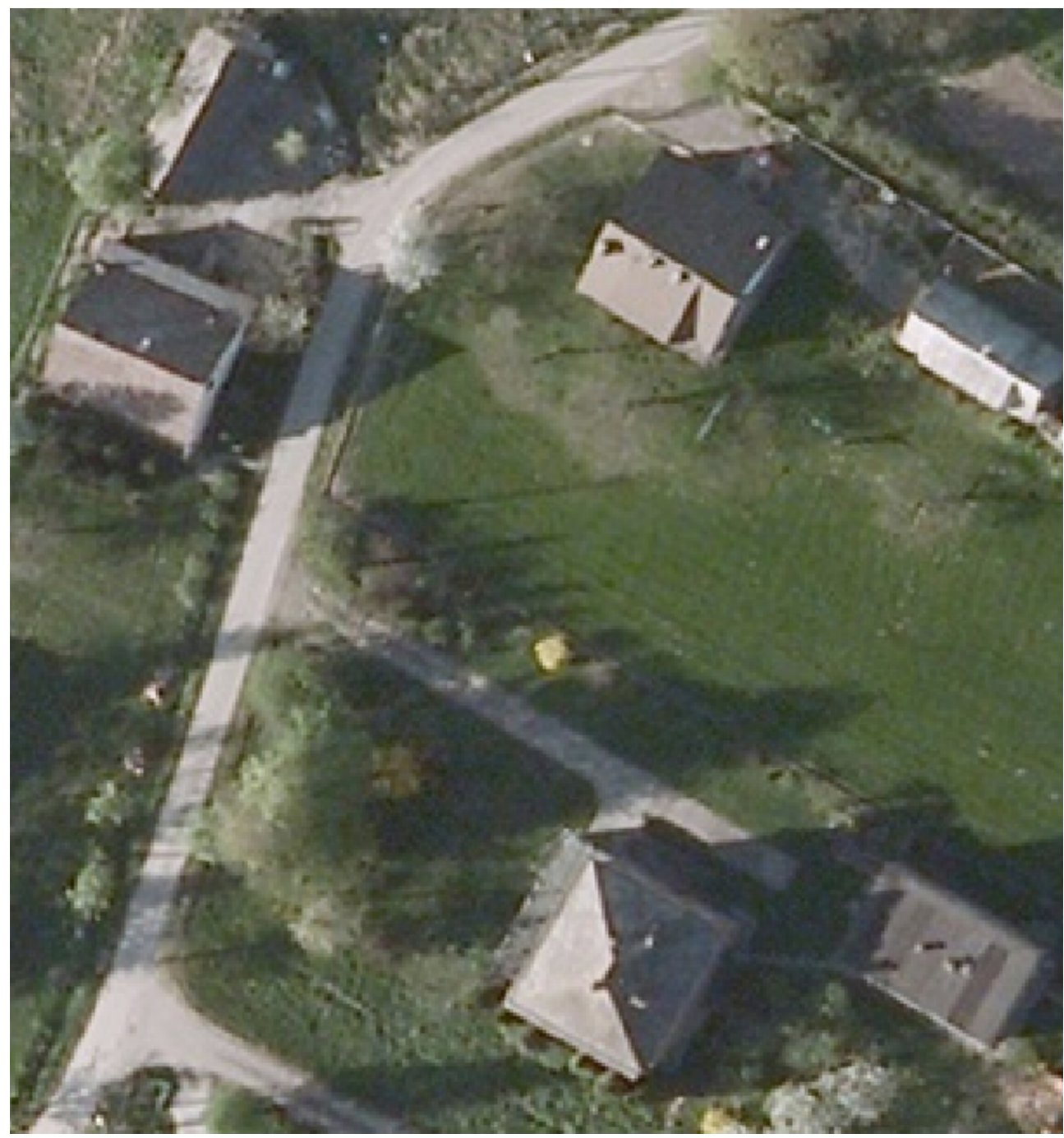

Fig. 10. Examples of roof coverings on orthophotomaps with $25 \mathrm{~cm}$ pixel size, the display scale 1:500

The result of the checks carried out on both types of orthophotomaps are presented in Table 3. Analysing obtained values, a significant prevalence of the correctness of asbestos-cement roofing identification is noticeable in case of using an orthophotomap with a smaller pixel. The error did not exceed $1 \%$. In contrast, the error results on orthophotomap with $25 \mathrm{~cm}$ pixel were at the level of about $20 \%$. This is reflected in the difficulties encountered during vectorisation and further confirms the lack of possibility to automate the identification process on orthophotomaps with a larger ground pixel. 
a)

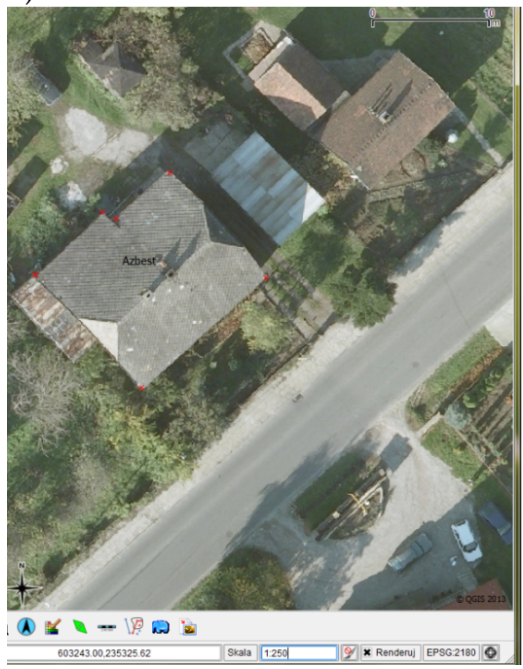

b)

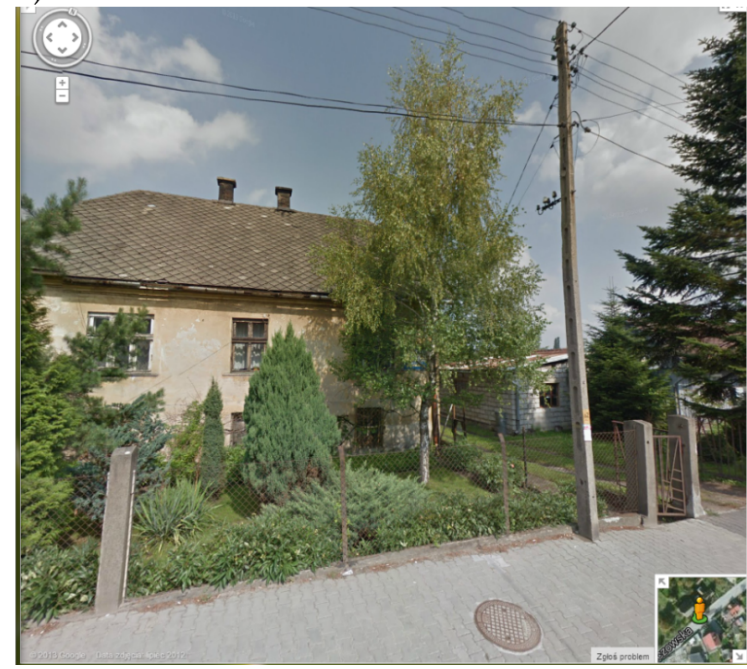

Fig. 11. Verification of asbestos-cement roofing, a) orthophotomap in the QGIS;

b) view on the vectorized roof in Google Street View application

Table 3. Results of the verification of vectorized asbestos-cement roofs

\begin{tabular}{|c|c|c|c||}
\hline $\begin{array}{c}\text { Pixel size of } \\
\text { orthophotomap } \\
\text { [cm] }\end{array}$ & $\begin{array}{c}\text { Number of } \\
\text { vectorized } \\
\text { asbestos-cement } \\
\text { roofs }\end{array}$ & $\begin{array}{c}\text { Number of incorrectly } \\
\text { vectorized asbestos-cement } \\
\text { roofs (share \%) }\end{array}$ & $\begin{array}{c}\text { Number of missed } \\
\text { asbestos-cement roofs } \\
\text { (share \%) }\end{array}$ \\
\hline \hline 5 & 82 & $1(1.2)$ & $1(1.2)$ \\
\hline 25 & 128 & $16(12.5)$ & $8(6.3)$ \\
\hline
\end{tabular}

Based on the works carried out, it can be concluded that the analysis of data from the visible range in order to distinguish different roofing sheets does not minimize the work of the operator and in case of using data with a wide range it does not provide satisfactory results.

\section{Summary}

What should be stressed at the beginning is the importance of the problem of identification and utilisation of asbestos-cement materials. It results from two aspects, namely the negative impact of asbestos materials on human health and the applicable law.

The presented case study literature reveals wide possibilities of using air hyperspectral imaging, the use of which enables the identification of asbestos cement 
at a high level of $90 \%$. Additional information obtained from the conducted hyperspectral analyses is the indication of two very narrow spectral ranges for which the asbestos-cement roofing sheets differ significantly from other materials: SWIR with $2.32 \mu \mathrm{m}$ wavelength and TIR with $9.44 \mu \mathrm{m}$ wavelength.

After carrying out analyses on the available orthophotomaps it was concluded that the results obtained in relation to roofing materials identification are not satisfactory. Identification at sufficient accuracy level was achieved only on orthophotomaps with a ground pixel of a few centimetres, however, there is a small availability of such type of imaging for the areas of the whole country. What is more, no possibility was noticed of systematizing analyses and using automation process, without additional multi-threaded image processing.

Based on own experiences collected and available materials it can be concluded that there are facts that indicate the possibility of using hyperspectral remote sensing with the ground pixel of $5 \mathrm{~m}$, in order to create a coherent system that enables efficient, rapid and repeatable identification of asbestos-cement roofing sheets. An important aspect of this case is pressing need for conversion from research methods to technological solutions. It is important because of the possibility of obtaining refunding of the total costs of dismantling, transport and disposal of construction materials in the form of asbestos-cement roofing sheets in Poland. In the absence of appropriate technology, the use of high resolution orthophoto assisted by Google Street View is proposed. However, it should be borne in mind that such approach requires a thorough discussion. The developed technology that will allow to detect asbestos components and gather obtained information in the form of digital maps in conjunction with other available GIS layers can become a useful tool for public administration authorities in determining location of asbestos roofs and in the efficient management of their utilisation.

\section{References}

[1] Bassani C., Cavalli R. M., Cavalcante F., Cuomo V., Palombo S., Pascucci S., Pignatti S.: Deterioration status of asbestos-cement roofing sheets assessed by analyzing hyperspectral data. Remote Sensing of Environment, vol. 109, 2007, pp. 361-378.

[2] Bish D.L., Chipera S.J.: Problems and solutions in quantitative analysis of complex mixtures by X-ray powder diffraction. Advances in X-ray Analysis, vol. 31, 1988, pp.295-308.

[3] Boardman J.W., Kruse F.A., Green R.O.: Mapping target signatures via partial unmixing of AVIRIS data. [in:] Summaries of the Fifth Annual JPL Airborne Earth Science Workshop, January 23-26, 1995, JPL Publication 95-1, vol. 1, 1995, pp. 23-26. 
[4] Czajka K.: Zastosowanie zdjęć lotniczych w inwentaryzacji miejsc skażonych azbestem. Ekorpofit (Dokładniej i Taniej), vol. 2, 2001, pp. 17-18.

[5] Fiumi L., Campopiano A., Casciardi S., Ramires D.: Method validation for the identification of asbestos-cement roofing. Applied Geomatics, vol. 4, Issue 1, 2012, pp. 55-64.

[6] Gao B.-C., Heidebrecht K.B., Goetz A.F.H.: Atmosphere Removal Program (ATREM) User's Guide, Version 3.1. Center for the Study of Earth From Space (CSES), Cooperative Institute for Research in Environmental Sciences (CRES), University of Colorado, Boulder, 1999.

[7] Green A.A., Berman M., Switzer P., Craig M.D.: A transformation for ordering multispectral data in terms of image quality with implications for noise removal. IEEE Transaction on Geoscience and Remote Sensing, vol. 26, no. 1, 1988, pp. 65-74.

[8] Harsanyi J.C., Chang C.I.: Hyperspectral image classification and dimensionality reduction: An orthogonal subspace projection approach. IEEE Transactions on Geoscience and Remote Sensing, vol. 32, 1994, pp. 779-785.

[9] Marino C.M., Panigada C., Busetto L.: Airborne hyperspectral remote sensing applications in urban areas: asbestos concrete sheeting identification and mapping. [in:] IEEE/ISPRS Joint Workshop on Remote Sensing and Data Fusion over Urban Areas: Rome, 8-9 November 2001, IEEE, 2001, pp. 212-216.

[10] Moore D.M., Reynolds R.C.: X-ray diffraction and the identification and analysis of clay minerals. $2^{\text {nd }}$ ed. Oxford University Press, 1997.

[11] Nofer Institute of Occupational Medicine. [on-line:] http://www.imp.lodz. pl/home_pl/o_instytucie/reg_and_databases/osrodek_referencyjny_azbest/ skutki_zdrowotne_dzialania_azbestu/ [accessed: November 2013].

[12] Pinho C.M.D., Silva F.C., Fonseca L.M.C., Monteiro A.M.V.: Intra-Urban Land Cover Classification from High-Resolution Images Using the C4.5 Algorithm. The International Archives of the Photogrammetry, Remote Sensing and Spatial Information Sciences, vol. 37, part B7, 2008, pp. 695-700.

[13] POKA: Programme for Asbestos Abatement in Poland 2009-2032, Annex to the Resolution No. 39/2010 of the Council of Ministers of 15 March 2010.

[14] Ruff S.W., Christensen P.R., Barbera P.W., Anderson D.L.: Quantitative thermal emission spectroscopy of minerals: A laboratory technique for measurement and calibration. Journal of Geophysical Research, vol. 102(14), 1997, pp. 899-913.

[15] Salisbury J.W., Walter L.S., Vergo N., D'Aria D.M.: Infrared spectra of minerals (2.1-25 micrometers). Johns Hopkins, Baltimore 1991.

[16] Small C.: High spatial resolution spectral mixture analysis of urban reflectance. Remote Sensing of Environment, vol. 88, 2003, pp. 170-186.

[17] The Mineral and Energy Economy Research Institute of the Polish Academy of Sciences. [on-line:] www.min-pan.krakow.pl/dane-kontaktowe-pracown ikow/637-prace-zrealizowane-2001.html [accessed: July 2014]. 
[18] Vane G., Goetz A.F.H.: Terrestrial Imaging Spectroscopy. Remote Sensing of Environmental, vol. 24, 1988, pp. 1-29.

[19] Virta R.L.: Geology, Mineralogy, Mining, and Uses. U.S. Department of the Interior, U.S. Geological Survey, Open-File Report 02-149, 2003 [on-line:] http:// minerals.usgs.gov/minerals/pubs/commodity/asbestos/ [accessed: November 2013].

[20] Welch R.: Spatial resolution requirements for urban studies. International Journal of Remote Sensing, vol. 3(2), 1982, pp. 139-146. 